\title{
Erratum to: Study of in-vitro metabolism of selected antibiotic drugs in human liver microsomes by liquid chromatography coupled with tandem mass spectrometry
}

\author{
Malgorzata Szultka-Mlynska ${ }^{1,2} \cdot$ Boguslaw Buszewski $^{1,2}$
}

Received: 13 October 2016 / Accepted: 13 October 2016/Published online: 26 October 2016

(C) Springer-Verlag Berlin Heidelberg 2016

Erratum to: Anal Bioanal Chem

DOI:10.1007/s00216-016-9929-6

Unfortunately, there was a mistake in Table 2 and Fig. 4 of this contribution. Please find the correct Table 2 and Fig. 4 below.

The online version of the original article can be found at http://dx.doi. org/10.1007/s00216-016-9929-6.

Malgorzata Szultka-Mlynska

szultka.malgorzata@wp.pl

1 Department of Environmental Chemistry and Bioanalytics, Faculty of Chemistry, Nicolaus Copernicus University, Gagarin 7,

87-100 Torun, Poland

2 Center for Modern Interdisciplinary Technologies, Nicolaus

Copernicus University, Wilenska 4, 87-100 Torun, Poland 
Table 2 The retention times, mass characteristics and elemental composition of the $[\mathrm{M}+\mathrm{H}]^{+}$of studied antibiotic drugs and their potential metabolites.

\begin{tabular}{|c|c|c|c|c|c|c|c|c|}
\hline Compound & Metabolites & Chemical structure & $\begin{array}{l}\text { Retention } \\
\text { time (min) }\end{array}$ & {$[\mathrm{M}+\mathrm{H}]^{+}$} & $\begin{array}{c}\text { MS/MS } \\
\text { fragments }\end{array}$ & Elemental composition & Metabolic reaction & $\begin{array}{c}\text { Prediction } \\
\text { by }\end{array}$ \\
\hline \multirow[t]{2}{*}{$\begin{array}{c}\text { CIP } \\
m / z=332 \\
0\end{array}$} & CIP-M1 & & 4.23 & 288 & $\begin{array}{l}172,245 \\
261\end{array}$ & $\mathrm{C}_{16} \mathrm{H}_{18} \mathrm{FN}_{3} \mathrm{O}$ & Decarboxylation & $\begin{array}{c}\text { HLM, } \\
\text { urine } \\
\text { sample, } \\
\text { Caco-2 }\end{array}$ \\
\hline & CIP-M2 & & 3.59 & 508 & $\begin{array}{l}287,315 \\
\quad 319\end{array}$ & $\mathrm{C}_{23} \mathrm{H}_{26} \mathrm{FN}_{3} \mathrm{O}_{9}$ & Glucuronidation & $\begin{array}{l}\text { HLM, } \\
\text { Caco-2 }\end{array}$ \\
\hline $\begin{array}{c}\text { FLU } \\
m / z=307\end{array}$ & FLU-M1 & & 4.15 & 323 & 175,273 & $\mathrm{C}_{13} \mathrm{H}_{13} \mathrm{~F}_{2} \mathrm{~N}_{6} \mathrm{O}_{2}$ & Hydroxylation & $\begin{array}{c}\text { HLM, } \\
\text { urine } \\
\text { sample, } \\
\text { Caco-2 }\end{array}$ \\
\hline \multirow{2}{*}{ 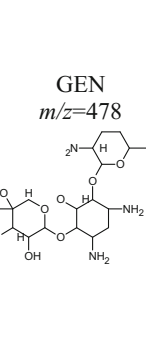 } & GEN-M1 & & 9.63 & 520 & $\begin{array}{c}216,360 \\
365\end{array}$ & $\mathrm{C}_{23} \mathrm{H}_{45} \mathrm{~N}_{5} \mathrm{O}_{8}$ & Acetylation & $\begin{array}{c}\text { HLM, } \\
\text { urine } \\
\text { sample, } \\
\text { Caco-2 }\end{array}$ \\
\hline & GEN-M2 & & 11.47 & 654 & 318,321 & $\mathrm{C}_{27} \mathrm{H}_{51} \mathrm{~N}_{5} \mathrm{O}_{13}$ & Glucuronidation & $\begin{array}{l}\text { HLM, } \\
\text { Caco-2 }\end{array}$ \\
\hline \multirow{3}{*}{ KLI } & KLI-M1 & & 6.12 & 411 & 327,363 & $\mathrm{C}_{17} \mathrm{H}_{31} \mathrm{ClN}_{2} \mathrm{O}_{5} \mathrm{~S}$ & S-dealkylation & $\begin{array}{c}\text { HLM, } \\
\text { urine } \\
\text { sample, } \\
\text { Caco-2 }\end{array}$ \\
\hline & KLI-M2 & & 5.67 & 411 & 375,393 & $\mathrm{C}_{17} \mathrm{H}_{31} \mathrm{ClN}_{2} \mathrm{O}_{5} \mathrm{~S}$ & N-dealkylation & $\begin{array}{c}\text { HLM, } \\
\text { urine } \\
\text { sample, } \\
\text { Caco-2 }\end{array}$ \\
\hline & KLI-M3 & & 4.94 & 441 & $\begin{array}{c}393,405, \\
423\end{array}$ & $\mathrm{C}_{18} \mathrm{H}_{33} \mathrm{ClN}_{2} \mathrm{O}_{6} \mathrm{~S}$ & S-oxidation & $\begin{array}{c}\text { HLM, } \\
\text { urine } \\
\text { sample, } \\
\text { Caco-2 }\end{array}$ \\
\hline \multirow{3}{*}{ MET } & MET-M1 & & 4.25 & 142 & 97,112 & $\mathrm{C}_{6} \mathrm{H}_{11} \mathrm{~N}_{3} \mathrm{O}$ & $\begin{array}{l}\text { Reduction of nitro } \\
\text { groups }\end{array}$ & $\begin{array}{l}\text { HLM, } \\
\text { Caco-2 }\end{array}$ \\
\hline & MET-M2 & & 3.98 & 188 & 95,126 & $\mathrm{C}_{6} \mathrm{H}_{9} \mathrm{~N}_{3} \mathrm{O}_{4}$ & $\begin{array}{l}\text { Oxidation of aliphatic } \\
\text { chains }\end{array}$ & $\begin{array}{c}\text { HLM, } \\
\text { urine } \\
\text { sample, } \\
\text { Caco-2 }\end{array}$ \\
\hline & MET-M3 & $\mathrm{C}_{6} \mathrm{H}_{8} \mathrm{O}_{6}$ & 3.66 & 348 & 127,142 & $\mathrm{C}_{12} \mathrm{H}_{17} \mathrm{~N}_{3} \mathrm{O}_{9}$ & Glucuronidation & $\begin{array}{l}\text { HLM, } \\
\text { Caco-2 }\end{array}$ \\
\hline
\end{tabular}


Fig. 4 Total ion chromatograms and mass spectra of gentamicin and their potential metabolites after incubation with Caco-2 cell line: (a) after $6 \mathrm{~h}$, (b) after $12 \mathrm{~h}$, (c) after $24 \mathrm{~h}$, , d) UV chromatogram after $12 \mathrm{~h}$ and $24 \mathrm{~h}$. Mass spectrometric detection was carried out in ESI(+) mode

\section{a}

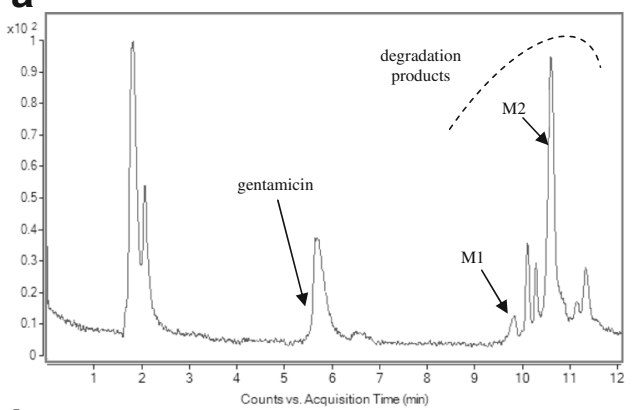

b

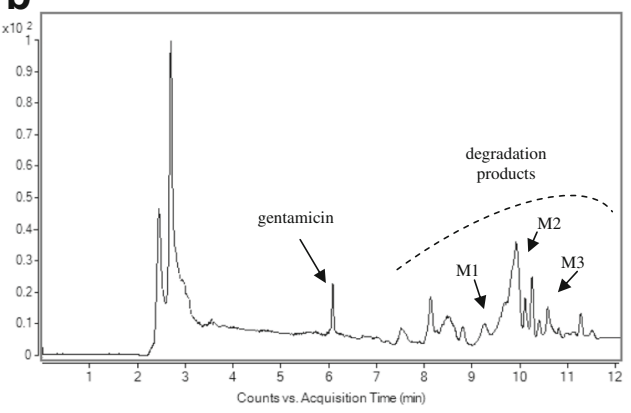

C

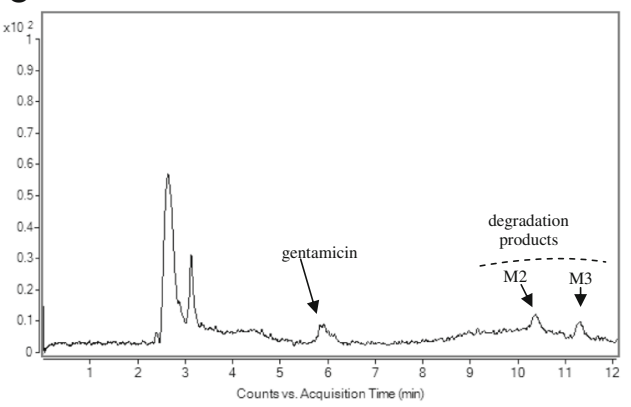

d

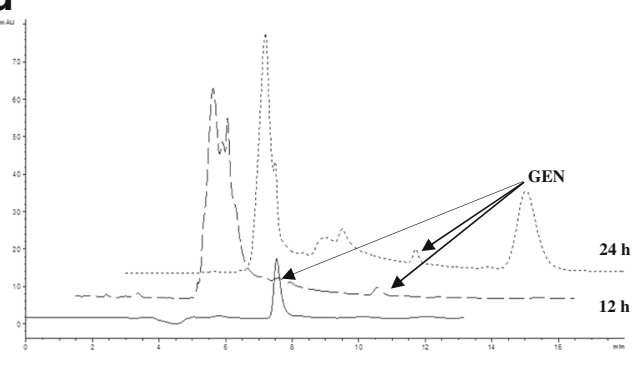

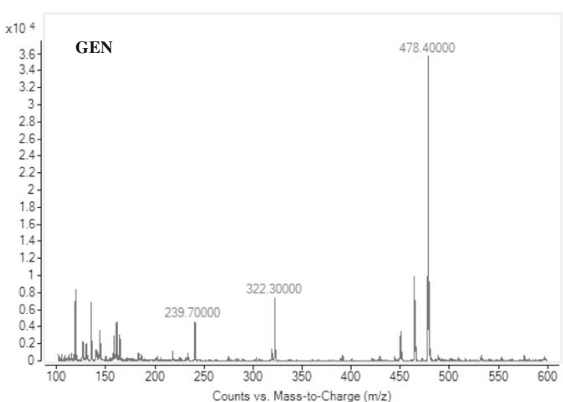
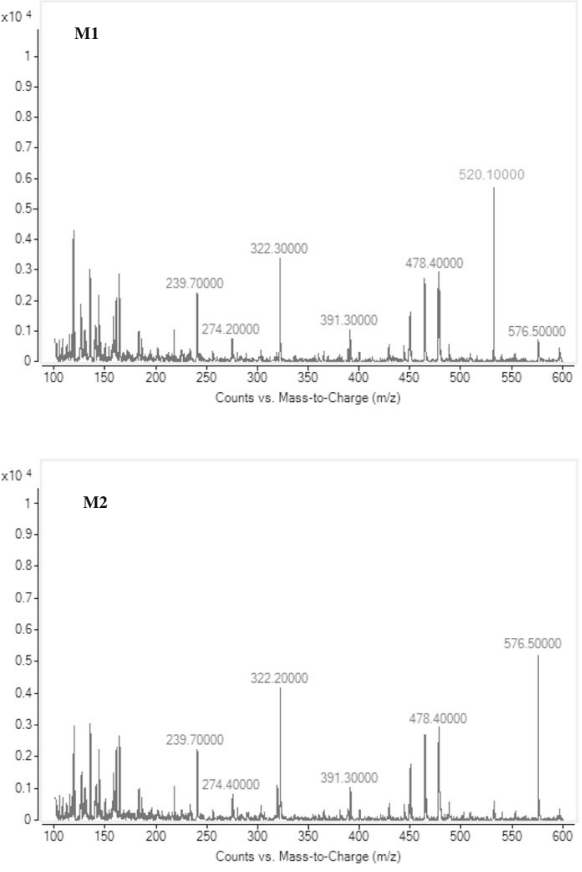

M3

M3

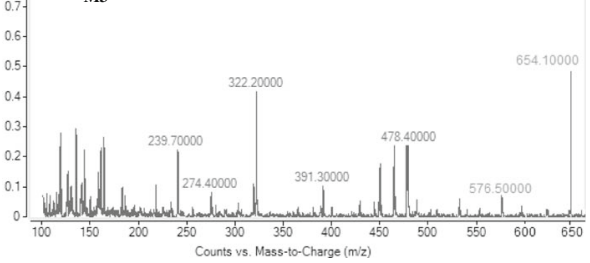

